\section{No distinction between male and female circumcision}

SIR

Female circumcision is ignored in many if not most of the Arab and Muslim countries; it is practised in Sudan (98 per cent), Somalia (98 per cent) Egypt (more than 75 per cent) and a few other Arab and Muslim countries. It has triggered a passionate public debate in the West. This debate has found somewhat of an echo in the Arab and Muslim world but some Muslim religious centres such as $\mathrm{Al}$ Azhar in Egypt, the most important Islamic Centre in the world, try to justify it by recourse to sunnah, the tradition of the prophet Mohammed.

Male circumcision is practised by all Muslims and Jews and also by some Christians (100 per cent in Egypt, 60 per cent in the USA). This practice among Muslims derives from the practice of the Jews: each Muslim must be circumcised like Abraham, who is considered a model man.

For different reasons, the debate against male circumcision is still taboo in Western, Arab and Muslim countries. Why?

1. Doctors and other paramedical groups profit by the operation of circumcision and one can hardly expect them willingly to reduce their income. Circumcision constitutes a lucrative industry in the United States.

2. Because of the opposition of the religious communities, in particular the Jewish community. The Western world has passed laws prohibiting female circumcision, but dares not do the same for male circumcision for fear that they will be considered anti-semitic by the Jews. The so-called 'medical' justifications for male circumcision were formulated principally by Jewish doctors. One must note, however, that even the voice of American Jews is being added to the cry against the practice of circumcision.
3. Because international organisations refuse to involve themselves in this issue. They are also afraid of being considered anti-semitic. These organisations, responsible for overseeing the respect of human rights, are always ready to criticise - correctly so female circumcision, but have become accomplices in the violation of the rights of male infants to an intact body.

There is no reason to distinguish between male and female circumcision: both are mutilations of healthy sexual organs of non-consenting children. There is no justification for such mutilations. If the clitoris and the foreskin were useless, Nature would not have made them. Furthermore, concerning Muslims, both practices violate the Koran: 'Our Lord, You did not create all this in vain' (3:191); ' $[\mathrm{He}]$ perfected everything He created' (32:7). Despite these two versus, Muslims systematically practise male circumcision.

It is imperative to leave the child intact until the age of 18 when he will have the freedom to decide for himself whether he wants to be circumcised or not. He is then free even to have his ears amputated if he chooses, but one does not have the right forcibly to remove his body parts when he is a baby.

In my opinion, a God who demands that his believers be mutilated and branded on their genitals the same as cattle, is a God of questionable ethics. It could be legitimate to perform either male or female circumcision, as any other surgery, for specific, extremely rare, medical reasons on specific individuals. But arbitrarily to mutilate children, boys or girls, under the pretext that it is for their own good, shows the influence of cynicism and/or fanaticism.

I would like to see the readers of your journal engage in this ethical argument. I developed this question in a recent article (1). For those who are interested, The Fourth International Symposium on Circumcision will be held at the University of Lausanne (Switzerland) on the 9-11 August 1996. This symposium will deal with both male and female genital mutilations. (For more information about this symposium, contact NOCIRC, POB 2512, San Anselmo, California 94979-2512, fax: 0014154889660 , tel: 0014154889883 ).

\section{Reference}

(1) Aldeeb Abu-Sahlieh S. To mutilate in the name of Jehovah or Allah. Medicine and law 1994; 13, 7/8: 574-622.

SAMI A ALDEEB ABU-SAHLIEH Doctor of Law,

Graduate in Political Sciences and Staff Legal Advisor in Charge of Arabic and Muslim Law at the Swiss Institute of Comparative Law, Lausanne, Switzerland

\section{An ethical approach to HIV carriage and AIDS}

SIR

Prevention of the spread of HIV relies above all and fundamentally on patients, or more accurately on healthy carriers and all those who request tests for AIDS. All our society does is to monitor the disease through specialised consultations, agencies and various types of committees. It is up to seropositive patients themselves to stop the epidemic. It is a hard task which requires courage, maturity and a sense of civic duty.

It is vital to overcome inertia and find a new system of ethics which is no longer medical only, ie, applying to doctors, but is also to be adhered to by patients. It must be recognised that, although the task is difficult, there are signs of improvement in people's behaviour and certain groups (homosexuals, for instance) are handling seropositivity more and more positively. In these groups, the disease is 